\title{
Recepción y análisis de la representación de Viudas, de Ariel Dorfman.
}

\section{The Reception and Analysis of the Performance of Widows, by Ariel Dorfman.}

\author{
Hyerim Hong \\ Universidad Nacional de Seúl (COREA DEL SUR) \\ CE: hhr9753@snu.ac.kr ID ORCID: 0000-0001-9082-8909
}

DOI: $10.32870 /$ sincronia.axxiii.n76.24b19

(C) $\mathrm{BY} \cdot \mathrm{NC}$

Esta obra está bajo una Licencia Creative Commons Atribución-NoComercial 4.0 Internacional

Recibido: 25/03/2019

Revisado: 06/04/2019

Aprobado: 23/05/2019

\section{RESUMEN}

El presente estudio analiza Viudas, una obra de teatro de Ariel Dorfman, como una representación y un texto literario. A través de las reseñas críticas sobre varios casos de representación de Viudas en los países de habla no hispana, se averigua cómo el drama sobre los desaparecidos de América Latina fue recibido por el público en el mundo. Los críticos de Estados Unidos, Brasil y Corea del Sur mostraron diferentes opiniones y juicios sobre el tema debido a la experiencia sociohistórica de cada país y a la dirección de elementos no lingüísticos. El análisis del guion se enfoca en los aspectos no realistas que constituyen un reto al interpretarse en el escenario, para hacer sugerencias sobre sus direcciones. El narrador, el río y el carácter poético del guion pueden resultar más efectivos y coherentes con ejecuciones adecuadas.

Palabras clave: Teatro. Reseña crítica. Interpretación. Historia. América Latina. 


\begin{abstract}
:
The present study analyzes Widows, a play written by Ariel Dorfman, as a theatrical performance and a literary text. Through the critical reviews about various cases of performance of Widows in nonSpanish speaking countries, we find out how the drama on the disappeared of Latin America was received by audiences around the world. The critics of the United States, Brazil and South Korea showed different understandings about the theme due to the socio-historic experiences of each country and the direction of non-linguistic elements. The analysis of the script focuses on the nonrealistic aspects that present a challenge when being interpreted on stage, to make suggestions on its direction. The narrator, the river, and the poetic character of the script can be more effective and coherent with appropriate performances.
\end{abstract}

Keywords: Theatre. Critical review. Interpretation. History. Latin America.

\title{
I. Introducción: Teatro de los desaparecidos
}

Entre los numerosos textos artísticos que tratan de las dictaduras en los países latinoamericanos en la segunda mitad del siglo XX, aparece con frecuencia el tema de los desaparecidos, a los que nunca se encontraron después de ser detenidos por las fuerzas dictatoriales. Ariel Dorfman, uno de los autores contemporáneos más destacados, se ocupa de dicho tema en tres obras de diferentes géneros. La última se llama Viudas (1996), la obra de teatro que nos ocupa aquí. Fue adaptada de la novela del mismo nombre de Dorfman, en colaboración con Tony Kushner. Después de estrenarse en 1991 (McClennen, 2010, pp. 186-187), el guion se incluyó en una colección en inglés sin el personaje del narrador y en otra en español con el narrador (McClennen, 2010, p. 187).

Viudas relata la historia de unas mujeres que esperan a los hombres desaparecidos de un pueblo llamado Camacho, ${ }^{1}$ adonde llega un nuevo capitán con la promesa de progreso económico a

\footnotetext{
${ }^{1}$ El nombre del pueblo, Camacho, puede pertenecer a cualquier región latinoamericana, pero también recuerda el río Mapocho de Santiago de Chile, donde el 24 de septiembre de 1973, después del golpe de Estado de Augusto Pinochet, "en los últimos cuatro días habían sido recuperados veintisiete cadáveres [...] y que algunos cuerpos presentaban señas
} 
cambio de olvidar el pasado. Sin embargo, poco después, llega un cadáver por el río y sucesivamente más, y las mujeres que no pueden renunciar a sus hombres quieren enterrarlos cuerpos. A pesar de las amenazas y a la conciliación del capitán, las mujeres dejan de conformarse y deciden enfrentar a los militares para reclamar la verdad sobre las desapariciones.

En nuestro estudio, analizaremos Viudas no solo como un texto literario sino también como una representación, porque un texto dramático existe para ser representado. Primero, trataremos de entender la recepción de la obra en varios países e idiomas a través de las reseñas críticas que evaluaron los elementos exitosos y fallidos de cada función. Luego, con base en el resultado de la primera parte y en el análisis del texto del guion, haremos sugerencias sobre la dirección de ciertos elementos que requieren atención especial al ponerlos en escena. Una conclusión provisional para la primera parte sería que la recepción está relacionada con la experiencia histórica de cada país y que depende de la ejecución de los componentes no lingüísticos. El foco de las sugerencias serán los aspectos no realistas, como el narrador, el río y el ambiente poético más la interpretación adecuada para cada componente.

La elección del corpus de la primera parte obedece a la disponibilidad del material crítico, para permitirnos examinar cada representación desde varios puntos de vista de diferentes críticos y comparar la recepción en países de habla no hispana. Sobre las funciones en español, solo quedan pocos documentos que aportan información breve, como la fecha, el lugar y el elenco, en forma de noticias. ${ }^{2}$ Sin embargo, ninguna de ellas fue revisada profesionalmente ni en una forma accesible, por eso, no es posible saber detalles de las representaciones. Por otro lado, se halla bastante información y registros críticos para usar como referencia acerca de las adaptaciones en los países de habla no hispana, sobre todo en los Estados Unidos, Brasil y Corea del Sur. Analizar los casos de

de tortura y mutilaciones" (Cusato, 2004, p. 58). El dato original procede de un cablegrama de la CIA de los Estados Unidos y muestra que el gobierno estadounidense intervino en el golpe y en la violencia que lo sucedió.

2 Por ejemplo, en 2001, Teatroxlaidentidad presentó Viudas como parte de un ciclo anual en el Teatro del Pueblo, en Argentina (Teatro X la identidad, 2001). El Teatro Universitario de la Universidad de Puerto Rico en Río Piedras puso Viudas en el escenario en noviembre de 2010 (Sube a escena la obra "Viudas" en el teatro Julia de Burgos de la UPR, 2010). Más recientemente, en marzo de 2017, en el Teatro Sidarte de Chile los egresados de la Escuela de Teatro Los Leones participaron en el festival de teatro EXIT con Viudas (Teatro Sidarte, 2017). 
los tres países es relevante por la intención que Dorfman tenía hacia los lectores de la novela, como dice: "I wanted them to ask themselves about the connections between my country and theirs, my present and their past, our present and their future" [Quería que se preguntaran a sí mismos sobre la conexión entre mi país y los suyos, mi presente y su pasado, nuestro presente y su futuro.] (Mail \& Guardian, 1997). Además, el drama se estrenó en los Estados Unidos en 1991, después de acabar la dictadura en Chile de Augusto Pinochet. Es evidente que Dorfman tenía en cuenta el mundo fuera de América Latina como el público de Viudas. Las críticas que trataremos en nuestro estudio comprobarán si Dorfman tuvo éxito en conectarse con el mundo de habla no hispana. ${ }^{3}$

\section{La recepción: fracaso en los Estados Unidos, éxito en Brasil y en Corea del Sur}

Por el carácter temporal de la representación teatral, es difícil estudiar una representación en su totalidad y comparar varias versiones en conjunto, más aún cuando han terminado. Así que solo queda estudiarlas a través de los registros escritos. Aquí se analizan cinco funciones de tres países, Estados Unidos, Brasil y Corea del Sur, con base en los comentarios de revistas, periódicos y estudios académicos. Seguiremos el orden cronológico: las funciones de 1991 y 2008 de los EE.UU., la de 2011 de Brasil y las de 2012 y 2014 de Corea del Sur.

El estreno mundial de Viudas tuvo lugar en Los Ángeles como Widows (1991), en el teatro Mark Taper Forum, por el grupo Center Theatre Group, bajo la dirección de Robert Egan. Sobre la representación, Drake (1991) escribió en el periódico Los Angeles Times una reseña titulada "Widows an Exercise in Artifice". Según dicha crítica, fue un fracaso artístico en general salvo el decorado, la luz y la originalidad del sonido. Para cumplir una intención demasiado política, el drama no tuvo la tensión necesaria y en vez de personajes vivos, solo se vieron unos aparatos al servicio de una idea. La universalidad y el carácter poético de las líneas las hizo tan abstractas que resultaron vacías y no provocaron una reacción de empatía en el público (Drake, 1991).

\footnotetext{
${ }^{3}$ En nuestro estudio solamente nos ocupan las reseñas de los críticos profesionales, las cuales se publicaron en periódicos, revistas profesionales y académicas. Sin embargo, sería injusto asumir que las opiniones de los profesionales representan las de todos los espectadores de una obra de teatro. Así que convendrá destacar que elegimos el corpus por su accesibilidad y entender que el análisis sobre una función se limita a dicho corpus.
} 
La segunda representación estadounidense, Widows (2008), fue en el 59E59 Theaters de Nueva York, bajo la dirección de Hal Brooks. Cuatro críticos que escribieron reseñas sobre la función estuvieron de acuerdo en que el tema central tenía un valor universal, pero que el texto dramático y la dirección no lograron captar la atención. Mientras que Propst (2008) señaló como el problema mayor el drama descentrado en muchas tramas secundarias y la distracción causada por la actuación poética del coro y del realismo mágico, Sommer (2008) dijo que el avance demasiado lento había reducido lo bueno de la actuación suave en un teatro muy pequeño. ${ }^{4}$ El crítico de New York Times sintió pena por aburrirse ya que la compasión y el horror que sentía el autor ante el tema no se habían reflejado en un drama convincente. Las líneas desafiladas, la actuación monótona y artificiosa, y la proximidad incómoda del escenario en medio de los asientos fueron sus razones (Isherwood, 2008). Por último, Thielman (2008) estaba casi molesto porque se sentía sacudido por un autor más interesado en inflamar pasiones que por hacer teatro. En dicha función, faltó la sutileza del dramay del decorado, y, por mayor culpa por parte del escritor que del director, terminó dando al público una lección simple de que el totalitarismo y las personas que lo sostienen son malvadas, según afirmaciones del crítico.

En suma, aunque los críticos estadounidenses entendieron la importancia del tema de Viudas, la obra resultó poco persuasiva o veraz para el público. Se ve que la preocupación que Dorfman sentía al escribir la obra teatral para el público de los EE.UU., se cumplió. El autor dijo:

Tony (Cushner) became in effect the bridge I had been looking for to enter the world of theater and reach the U.S. audience which I had found trouble in connecting to this particular story so removed politically and aesthetically from the typical American tradition. (Dorfman, 1998, citado por McClennen, 2010, p.186).

La representación en verdad tuvo problemas en conectarse con la tradición estadounidense, política y estéticamente hablando. Los críticos en común mencionaron como problemas la dicotomía

\footnotetext{
${ }^{4}$ El teatro B donde fue la representación tiene menos de cien asientos actualmente (59E59 Theaters, 2018). El artículo de Thielman (2008) informa que había 68 asientos y Sommer (2008) comenta que los espectadores se sentaron a los dos lados del escenario de plataforma, que era pequeño para un elenco de 18 personas.
} 
política demasiado forzada, la falta de tensión dramática y los personajes que aparecían inauténticos.

La representación brasileña Viúvas-Performance sobre a ausencia (2011) por un grupo teatral con interés especial en el activismo político, llamado Ói Nóis Aqui Traveiz, llamó mucha atención de los académicos. Los críticos la estudiaron en detalle y destacaron la importancia de la obra en el contexto socio histórico de Brasil.

Viúvas-Performance sobre a ausência se representó en una isla monumental llamada Ilha das Pedras Brancas o Ilha do Presídio, que había sido una prisión donde el gobierno dictatorial encarcelaba y torturaba a los subversivos en los años sesenta (Milaré, 2011, pp. 52-53). Los espectadores eran llevados a la isla en un barco escuchando a un escritor en exilio (Gomes, 2017, p. 41), y veían desde lejos a una anciana mirando hacia el río Guaíba. Desde la llegada, eran guiados por la isla para ver, a veces justo delante de ellos y a veces desde cierta distancia, la historia de las mujeres, lo cual les permitía interactuar con los actores. ${ }^{5}$

Los cuatro artículos que son el corpus de nuestro análisis destacan la importancia del lugar y del tiempo en que se desarrolló la función brasileña. En dicha isla, que mantiene su propia historia de los desaparecidos, el drama de Dorfman actuó como un invocador de memorias. Gomes Perini (2017, p. 42) Ilama a la isla "um lugar de memória", 6 y Milaré (2011, p. 52) dice que ciertas escenas inducían al espectador-participante los recuerdos de dicho espacio. Este efecto espacial se hacía más significativo con la circunstancia temporal de la representación, en septiembre de 2011, cuando Brasil estaba en proceso de crear la Comisión Nacional de la Verdad para investigar la violencia durante 40 años, inclusive la época de dictadura (Arias, 2011). Así que, en el nuevo contexto del giro a la memoria y al establecimiento de la Comisión de la Verdad, Viúvas abrió un nuevo conjunto de preguntas, como afirma Steuernagel (2017, p. 12), y permitió al público reflexionar sobre la dirección en que debería ir la sociedad brasileña.

\footnotetext{
${ }^{5}$ El video de la representación se halla en la colección de Tribo de Atuadores Ói Nóis Aqui Traveiz en la página web de Hemispheric Institute Digital Video Library (Hemispheric Institute Digital Video Library, 2011).

${ }^{6}$ Todas las cursivas son de los autores de cada cita.
} 
Además, las escenas simbólicas tuvieron una gran significación para los críticos. Melo (2013, p. 25) destacó que la intimidad de la acción en algunas escenas permitió al público ocupar un papel liminal entre testigos, personajes y espectadores, al tiempo que lo incitó a considerar suposición como víctimas de la ideología, cuanto como sujetos cómplices. Milaré $(2011$, p. 53) señaló los cuerpos que se descubrían en el suelo al final de la obra diciendo que allí se instauraba la poesía (Figura 1). Sobre dicha escena, Steuernagel (2017, p. 19) comentó que la presencia de los cuerpos de los actores era un tipo particular de presencia, la cual insistía en conjurar la ausencia de los desaparecidos. Se veía que las reacciones del público no eran solo de emoción sino también del cambio de pensamiento.

\section{Figura 1.}

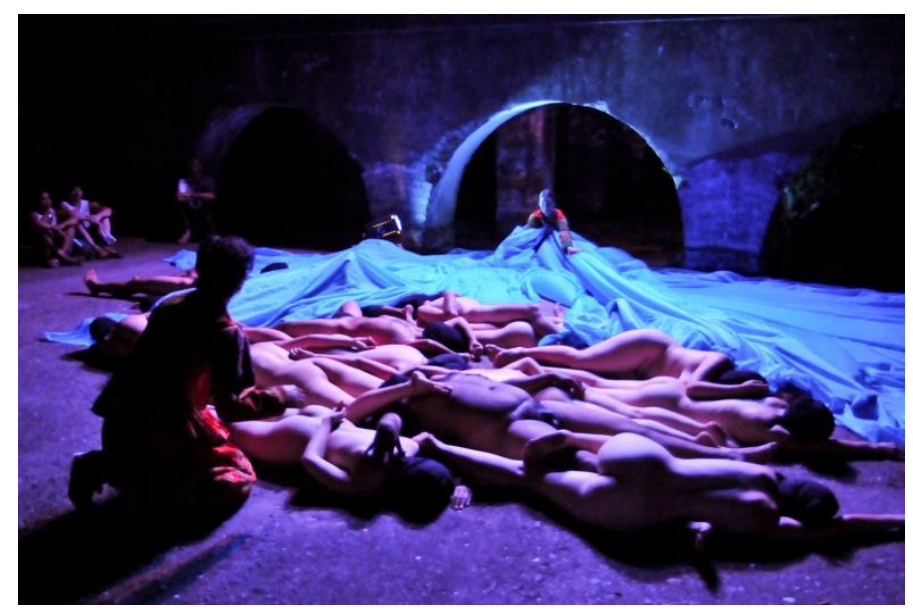

Los cuerpos de los desaparecidos. En Viúvas-Performance sobre a ausencia (Sagrado Cacete, 2011a)

En resumen, la adaptación de Viudas por Ói Nóis atrajo la atención académica por sus rasgos simbólicos de espacio, tiempo y dirección. Según los críticos, la importancia histórica de la isla hizo posible que el drama llegara a la conciencia del público y la oportunidad del estreno amplificó la implicación política. Así que Ói Nóis pudo convertir el drama universal de Dorfman en una versión 
muy brasileña y contemporánea. Además, el performance poético, que utilizó diferentes elementos visuales y sensoriales como la presencia de los cuerpos reales, trabajó en sinergia con el tema.

En Corea del Sur, Viudas fue representada en varias versiones por diferentes grupos de teatro, pero aquí trataremos solo la más célebre, Viudas $(2012,2014)$ del grupo Baeksugwangbu en los años 2012 y 2014, en Arko Art Center. Analizaremos tres reseñas de la función de 2012 y una de 2014. Primero, respecto a la representación de 2012, escribieron Eun-Kyung Lee, Kil-Su Kim y Soonja Hur. Para Lee (2012, p. 52), la expresión mediata resultó más fina, emocional y agregó profundidad al drama. En particular, el río, representado por una parte oscura en el medio del suelo, que varió de anchura con el cambio del carácter de las mujeres fue la clave del diseño escenográfico. Por desgracia, no hubo unidad entre los estilos diferentes de actuación y los coros, respectivamente compuestos por los soldados y las mujeres, fallaron en manifestar la circunstancia de las escenas. Sin embargo, dice que fue un intento valioso para un grupo civil en una situación difícil del teatro coreano (Lee, 2012, p. 50). Kim (2012, p. 133) elogió la poética de la representación, en especial la actuación del coro y el estilo simbólico y metafórico de las líneas. Las mujeres recitaron en colectivo al lado del río con panes y velas como si celebraran el funeral de los hombres (Figura 2). Así, se inducía un placer de juego audiovisual y de pensamiento, según el crítico. Además, para Kim (2012, p. 134) la elipsis y las metáforas frecuentes contribuyeron a la expansión de la imaginación del público y del valor artístico de la obra.

Figura 2.

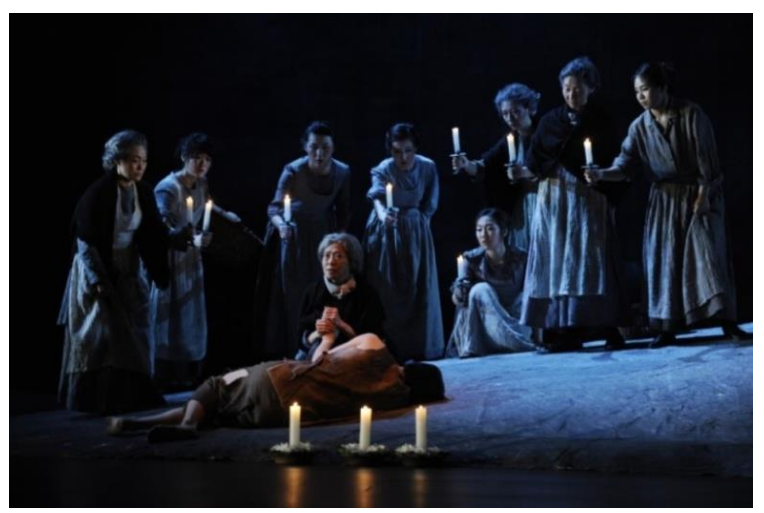

Las mujeres con velas ante un cuerpo al lado del río. En Viudas (Shin, 2018) 
Además, Hur (2013, p. 143), la presidente de la Asociación Internacional de Críticos Teatrales en Corea, también reconoció el valor de la tentativa del Baeksugwangbu en la crisis de los grupos dramáticos, a pesar de algunos defectos de la dirección. Informó que algunos críticos indicaron la falta de unidad estética y escenográfica y de la tensión producida por un sentido contemporáneo, pero Viudas (2012) ganó el premio de las tres mejores representaciones del año 2012.

Nam-suk Kim (2014, p. 69) en su reseña sobre la función del 2014, que fue una repetición de la del 2012, también percibió el río como un personaje. Con el cambio del río, las áreas de los dos lados del escenario fueron cambiando, y lo entendió el crítico como una señal de cambio interior de los personajes y la subversión del poder. Para dicho crítico, el recurso de las velas también tuvo un sentido similar. Contra la gran y dominante oscuridad del fondo, las velas, una tras otra, se fueron juntando y empezaron a formar una masa impresionante que recordó al público la posibilidad de expulsar la oscuridad (Kim, 2014, p. 71).

Las cuatro reseñas enfatizan la importante presencia de los elementos visuales que añadieron un significado simbólico. Sobre todo, la imagen del río que cambió de acuerdo con los personajes dejó una impresión fuerte en el público, e hizo posible compartir el dolor y la decisión de las mujeres. Tal vez por eso, las reseñas tienen un tono poético semejante a la obra. Había una disputa sobre la perfección artística, pero la admiración en general por el coro, el escenario y el performance muestra que los aparatos poéticos, que en los Estados Unidos no tuvieron éxito, lograron su intención en Corea del Sur.

Sobre las diferencias entre las recepciones de los Estados Unidos, Brasil y Corea, primero, podríamos atribuir diferentes niveles de empatía ante el tema político de Viudas al contexto y a la experiencia socio históricos de los espectadores. Para los críticos estadounidenses el asunto, aunque fuera universal y éticamente relevante para todos, les pareció abstracto o demasiado fuerte. Sin embargo, la dicotomía sobre la que el público estadounidense se sintió incómodo resultó como una reflexión de la realidad para los brasileños, que habían sufrido muchos años por la dictadura. Por eso, el tema tenía validez y actualidad como enfatizaron los críticos. Aunque los 
registros coreanos no subrayaron la experiencia de dictadura en Corea del Sur, el consentimiento expresado sobre el tema se infiere influido por el residuo de la memoria social. Segundo, la dirección de cada representación fue crucial. El drama original de Dorfman es poético y requiere que otros elementos estén en consonancia. Se ve que en las producciones estadounidenses las líneas poéticas condujeron mayormente el drama, pero recibieron críticas duras. Al contrario, otros elementos tuvieron más importancia y presencia que las líneas en las representaciones de los otros dos países. El río, el fuego y el coro llevaban un efecto mayor que las palabras solas o las hicieron más inteligibles. Ayudaron a entender la obra en su totalidad también, porque la grandeza o la profundidad de dichos elementos dieron a la obra el carácter épico que pretendía el texto original.

\section{El análisis del guion de Viudas y sugerencias para representarlo}

Pasemos ahora a analizar el texto del guion de Viudas en cuanto a los puntos que deben ser considerados al presentar la obra. El texto supone ciertos problemas para quienes deseen representar Viudas, y se puede decir que son iguales a las cualidades características de la obra. Son también los elementos determinantes del éxito al comprender la representación, porque podrían resultar confusos y aún débiles. Hablaremos de tres componentes, con referencia al apartado anterior: el narrador, el río y el aspecto poético de la obra.

La existencia de un narrador a primera vista no parece una parte consonante con el resto de la obra teatral. El personaje aparece solamente cinco veces, siempre después de un apagón y casi siempre solo, para contar anécdotas que parece que no se relacionan directamente con la trama central. De hecho, no existía en la primera versión de la adaptación teatral hecha con Tony Kushner, pero Dorfman sentía la necesidad de incluir un personaje para distanciar la tragedia, mientras que paradójicamente la llevaba más cerca al público y a su mundo (Mail \& Guardian, 1997), y por eso decidió agregar el narrador después del estreno. ${ }^{7}$ El narrador es un exiliado que atestigua y sufre

\footnotetext{
${ }^{7}$ Según McClennen, la versión final en inglés no incluye el narrador mientras que la versión en español lo tiene. La razón no se conoce, pero merece más investigación, como dice McClennen: "This difference may be a consequence of the distinct theatrical traditions in English and Spanish, but it certainly merits further study" [La diferencia puede ser
} 
junto con la acción de las mujeres y que escribe su historia en el extranjero. Resulta interesante que tiene muchas semejanzas con Dorfman y sus anécdotas elaboran las experiencias de exilio y de la tentativa frustrada de publicar la novela Viudas (1981) en Chile. Hasta reescribe su poema Traducción simultánea en su tercer monólogo. Este personaje, que simboliza al autor mismo, desempeña un papel de carácter fronterizo en tres maneras: como "el creador de esta historia" (Dorfman, 1996, p. 161), ${ }^{8}$ se sitúa entre los personajes ficticios y el público real. Está en un "país extraño y extranjero" (p. 93) como exiliado, por eso experimenta un estado entre la muerte o la desaparición de los hombres, y la sobrevivencia y el sufrimiento de las mujeres. Él mismo afirma que "el exilio es como la muerte" (p. 113). Por último, se cree ser "no [...] tan diferente de los intérpretes" (p. 145), porque no está dentro ni fuera de la historia y por eso "debo mirar desde lejos lo que no puedo remediar" (p. 145). Está en la frontera, y por eso sufre, pero también por la misma razón puede cumplir ciertas funciones que pueden proveer a la obra de una conexión más estrecha con el público. Así que, aunque suele ser omitido en muchas ocasiones, con una interpretación adecuada se añadiría mayor profundidad a la representación.

El narrador sirve para que el público considere su propia relación con el sufrimiento y la resistencia en la historia. Primero, cuando el narrador no informa su nacionalidad, hace posible que el público se acerque al dolor que lleva la dictadura y al dolor de los desaparecidos como si fuera su propio problema:

¿Mi patria? ¿Tanto importa? [...] Entre los tristes países del mundo que se ven por la televisión [...] donde unos pocos hombres deciden la vida o la muerte del resto de los habitantes, donde unos pocos deciden si un hombre va a desaparecer, si otro hombre va a partir al exilio. [...] No, no me parece necesario contarles cómo se llama mi país. (p. 94)

El crítico que trata sobre la representación brasileña también señala la función de universalizar del narrador como el factor que conecta la experiencia fácilmente a la historia propia de Brasil en la

consecuencia de las tradiciones teatrales distintas del inglés y del español, pero sin duda merece un estudio adicional.] (McClennen, 2010, p. 344).

${ }^{8}$ Citamos por esta edición. En adelante, se indicarán entre paréntesis las páginas de las citas. 
dictadura (Steuernagel, 2017, p. 12). Además, el narrador involucra al público en la historia central en una manera diferente a la de Bertolt Brecht. La existencia de un narrador para lograr el distanciamiento es típica del teatro brechitiano (Albuín, 1997, p. 53), pero el narrador de Dorfman afirma que no quiere ser un narrador brechtiano en su último monólogo: "No quiero transformarme en [...el] que viene desde fuera, determina confortablemente quién es malo, quién es bueno [...] un guía que encuentren familiar" (Dorfman, 1996, p. 173). Aquí se ve que su fin no es el razonamiento objetivo desde afuera. En cambio, Dorfman lo usa para un acercamiento o un entendimiento más empático, porque para Dorfman, el público considerado durante el preciso de adaptación al teatro que realizara con Kushnereran los estadounidenses (McClennen, 2010, p. 186), a quienes el narrador se refiere como "la gente acá [que] no tiene interés en ver" la desdicha de "la gente allá por mi país [que] no se atrevía a murmurar" (Dorfman, 1996, p. 173). Por eso, al contrario del narrador brechtiano, el narrador de Dorfman no deja al público que se identifique con él y no interrumpe al momento de subir la tensión, saliendo del escenario antes del desarrollo de una acción importante y dejando al público para que se concentre. Cuando termina sus últimas líneas, subraya: "no es mi historia" (p. 173), para que el público solo preste atención a las mujeres, y "sale, si es posible, por entre el público, yéndose del teatro mismo" (p. 173), como dice en la acotación. Después, las mujeres empiezan la acción de hacer fuego con las sillas de los desaparecidos, desarrollando el drama en su punto culminante.

El narrador es un personaje fronterizo que desempeña las funciones de universalizar el tema y de integrar a un público presuntamente indiferente. Dichas funciones enfatizan la historia central. Sin embargo, el narrador aparece en una dimensión espacial separada de las mujeres, y por eso si el narrador trata de cumplir su papel solo con sus palabras, no establecería más que un vínculo lógico con la trama mayor. Si se intentara provocar el acercamiento y una reacción empática, tendría que mostrarse que comparte el sufrimiento de las mujeres, aunque esté lejos. Así que proponemos que el narrador muestre una interacción afectiva con las mujeres. Por otro lado, hay que prestar atención a Fidelia, otro personaje con carácter fronterizo. Hay una escena donde el narrador aparece en el escenario con otros personajes, cuando Fidelia dice un monólogo sobre cómo "se 
llevaron a Alexis" (Dorfman, 1996, p. 147), en un ambiente fantástico. Desde entonces, Fidelia empieza a actuar de una manera diferente a los demás personajes, situándose "a una cierta distancia" y "mira[ndo] lo que sucede sin intervenir" (Dorfman, 1996, p. 149, en la acotación). Fidelia aún habla al público cuando devuelven a Alexis:

Alejandra: Alexis. (Alejandra se lleva a Alexis en la dirección opuesta. Fidelia se queda atrás, siempre a una distancia de las tumbas, casi como si habitara otra dimensión. Le habla al niño)

Fidelia: Di algo. Di "Ma". Todo bebé de tu edad sabe decir "Ma". (Mira hacia el público) Tal vez no va a decir nunca nada. Tal vez va a seguir callado toda la vida, sin contar nada de lo que ve. Hasta el día en que se muera. (Fidelia se va con el niño) (p. 150)

Además, igual que el narrador cuando habla por última vez y sale por entre el público, Fidelia aparece antes de la última acción de las mujeres para enfatizar el mensaje y sale también antes de la última acción:

Fidelia (al bebé): Tienes que aprender a hablar. Te va a hacer falta hablar. Hay cosas que vas a tener que contar. [...] Hay historias que piden a gritos ser contadas y, si no hay palabras todavía para ellas, se hacen piel para esperar el momento. El viento las lleva, y el humo, y el río, las palabras de cada historia encontrarán el camino hasta el lugar más solitario y lejano, siempre que haya alguien que quiera escuchar... [...] (Ella sale) (p. 190)

Se mueve y habla de un modo muy semejante al narrador, como su doble. Para que el público se dé cuente de esta relación, los dos personajes tienen que asemejarse a lo largo de la representación. Por ejemplo, se podría situar a Fidelia donde el narrador suele aparecer, o hacer que Fidelia use ciertos gestos particulares del narrador y vaya cambiando su tono de líneas como el narrador.

En segundo lugar, el río, que ofrece un reto para incluirlo en el escenario, tiene suma importancia en la obra porque funciona como el espacio de la acción y un tipo de personaje, como opinó Nam-Suk Kim. Como espacio, el río provee el fondo para los acontecimientos, y el más 
representativo es cuando viene un cadáver flotando por el agua. Es el espacio donde las mujeres aparecen en la primera escena lavando su ropa, donde entran para sacar los cuerpos y donde se reúnen para enfrentar a los soldados. Además, forma el ambiente de la acción, unas veces con el sonido y otras por aparecer en las palabras de los personajes; por ejemplo, cuando Sofía está "hablándole al río" (p. 100, en la acotación) o cuando el coro lo indica como el que sabe la verdad:

(El sonido del río sube. Las mujeres se levantan y lentamente forman un círculo en torno de la tumba)

Las mujeres: El agua sabe, el agua ha pasado por ahí, el agua tiene curiosidad, quiere saber [...] va a llevar las historias por los ríos de los ríos, contando y cantando las historias hacia el mar. (p. 153)

La existencia del río crea una atmósfera mítica por todo el texto, como si fuera un ser divino natural. Al mismo tiempo, da la sensación de ser un personaje, pero no es un ser objetivo o sobrehumano sino un actor que corresponde al mundo de las mujeres. El cambio de sonido y de acción del río ocurren de acuerdo con los cambios de las mujeres y sirven para reflejar sus interiores: “Escuchamos el sonido del río más fuerte que nunca. Vemos una figura en la oscuridad que forcejea con algo. [...] Por la luz de la vela vemos a Sofía sentada, mojada, teniendo en sus brazos otro cuerpo" (p. 129, en la dirección de escena). Aquí vemos que el río señala una nueva acción e indica cómo la resolución de Sofía debería ir aumentando. Incluso, refleja la mente de Cecilia, la traidora de las viudas, que enloquece de terror diciendo: "Theo está en el agua, yo vi... (Ella se suelta y comienza a correr hacia el río)" (p. 164). Brown (2013) analizó que el río está usado para externalizar la angustia psicológica de las mujeres ya que ayuda al proceso de curar sus cicatrices y recuperar su autoría de la historia. Por eso, la presencia del río en el escenario es indispensable. No basta con incluir solo el sonido o un efecto visual, el río tiene que estar. Los casos de Brasil y de Corea del Sur muestran cómo el río puede incluirse en el escenario (Figuras 3 y 4). En la pieza de 2008 en Nueva York, había un río en medio del escenario (Sommer, 2008), pero el espacio en total fue demasiado pequeño para representar la presencia fuerte de la naturaleza. Por eso, si es posible, 
es mejor que parezca sublime, como las tragedias clásicas griegas Antigone (Propst, 2008; Lee, 2012, p. 47), Las troyanas (Drake, 1991), y Hécuba (Lee, 2012, p. 47), las que los críticos encontraron semejanzas con el drama de Dorfman.

Figura 3.

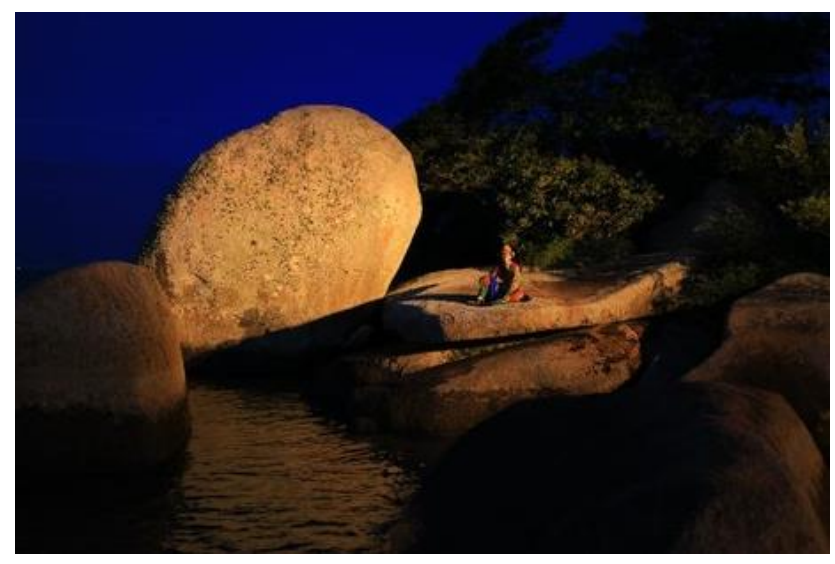

Sofía al lado el río. En Viuvas-Performance sobre a ausência (Sagrado Cacete, 2011b)

Figura 4.

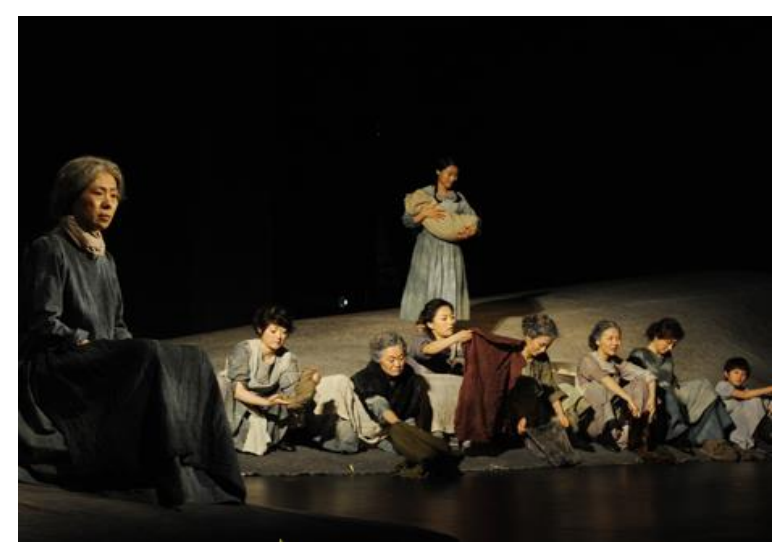

El río en medio de Sofía y las demás mujeres. En Viudas (Shin, 2018)

Pasemos a hablar del carácter poético de la obra. Ciertos críticos opinan que lo poético no concuerda con lo realista en la representación: "least speakable lines" (Thielman, 2008), "often pretentious poetic script" (Sommer, 2008), y "lyrical passages in which the women keen like a Greek 
chorus and sequences of magic realism only further distract from Dorfman's central story, making it feel aimless" [los pasajes líricos en donde las mujeres se lamentan como un coro griego y las secuencias de realismo mágico solo distraen de la trama central de Dorfman, haciendo que se sienta sin rumbo] (Propst, 2008). Sin embargo, lo poético representa el mundo de las mujeres frente al mundo práctico y lógico de los soldados:

Capitán: (Busca en su escritorio y saca un pedazo de papel) Este es el nuevo decreto de amnistía. ¿Sabe lo que es eso... una amnistía? Am-nis-tía. [...] Si han tenido problemas con el gobierno, ahora pueden entregarse. [...]

Sofía: Vine para que me dieran permiso para enterrar a mi padre. [...] Él llegó hasta mí... desde la tierra de los muertos. Mandó su cuerpo. Porque quiso que yo lo enterrara. (Dorfman, 1996, pp. 120-121)

Las imágenes y las acciones expresan más de lo que pueden decir las palabras. Lo cotidiano y lo natural como el sueño de coser, los panes, las sillas, el fuego, el río y los sonidos son símbolos de los pensamientos y las emociones de las viudas:

Mientras tanto, Fidelia ha estado levantado un costal. Se rasga y los granos se desparraman por todo el escenario. Hay un silencio total. Nadie se mueve. Todas miran los granos desparramados. Alejandra, y de a poco las otras, con las mujeres del valle, se ponen de rodillas y empiezan a recoger, los granos [...]. Una de las mujeres comienza a llorar. [...] Sofía se levanta lenta, dolorosamente. Ella deja caer el puñado de cereal que ha recogido. Camina hasta la mujer que llora [...]. Se calma el llanto de la mujer. Sofía se va. [...] Escuchamos el sonido del río, aumentando de volumen, volviéndose amenazante (p. 128, en la dirección de escena, las cursivas pertenecen al texto).

La caída de los granos termina el grito de Alejandra diciendo: “mi marido no ha muerto" (p. 128), y muestra cómo las mujeres siguen la vida con sus corazones rotos. El sonido amenazante del río continúa hasta la próxima escena donde Sofía saca el segundo cuerpo, mostrando su resolución de seguir la lucha. La interpretación en el escenario debe presentar dichos elementos con un impacto 
que se corresponda con su importancia, y hacer que el ambiente épico y sublime de la verdad prevalezca sobre el mundo de violencia y opresión. Un ejemplo sería al final de la obra cuando, a pesar de la amenaza de disparar del ejército, las mujeres "avanzan hacia los soldados, [...] quizás bailando, quizás cantando, quizás tan solo moviéndose hacia el público" (p. 191, en la dirección de escena). Las líneas poéticas serían más efectivas con ayuda de otros aparatos audiovisuales. En el teatro, se puede lograr un mayor efecto a través de la vista y el audio, y da un mensaje más intuitivo a los espectadores que las líneas solas, como la versión coreana que interpretó la escena de las velas y la canción del coro para estimular la imaginación del público. Por eso, se recomienda que se aprovechen los efectos sensoriales para enfatizar la presencia y la importancia de lo poético del mundo interior de los personajes femeninos.

\section{Conclusión: Teatro como encarnación de historia}

Al revisar varias versiones de representación y el guion de Viudas de Ariel Dorfman, se aprecia que se necesitan diversos intentos de interpretación y ejecución de un texto dramático para llegar a comprender mejor la obra. El fracaso de implicar al espectador en los Estados Unidos, y el éxito en Brasil y Corea del Sur de llevar al público reflexiones significativas, sirven como ejemplos de dichos intentos. Las diferentes opiniones en las reseñas analizadas proveen puntos de vista de la recepción a considerar al poner la obra en escena en el futuro. Con base en los resultados y en el análisis textual, nuestro estudio enfatiza la exigencia de la interacción del narrador con las mujeres, la presencia del río y el uso de imaginería para destacar el carácter poético de la obra.

Como se ve en obras con temas que tienen una relación estrecha con la realidad, como ocurre en Viudas, el teatro posee una capacidad única de reanimar una historia olvidada o minoritaria. Es posible a través de recursos como el sonido, la vista, el cuerpo, que son los puntos fuertes del teatro comparando con la forma escrita de literatura. Tal vez, eso motivó a Dorfman para transformar la novela en drama. El teatro permite al público experimentar una historia como si fuera actual e inmediata. Comparar las experiencias de los espectadores y preguntar qué más puede encontrarse dentro de un texto dramático, como hemos intentado aquí, enriquecerán dicho 
poder del teatro en las creaciones venideras y ayudarán a salvar historias que no se deberían ignorar ni olvidar.

\section{Referencias}

59E59 Theaters (2018). Our Spaces. Obtenido el 19 de diciembre de 2018 de https://59e59.org/about/spaces/

Abuín, Á. (1997). El narrador en el teatro La mediación como procedimiento en el discurso teatral del siglo XX. Santiago de Compostela: Universidade de Santiago de Compostela.

Arias, J. (20 de noviembre de 2011). Brasil crea una Comisión de la Verdad sobre la dictadura, Internacional. El País. Internacional. Obtenido el 20 de diciembre de 2018 de https://elpais.com/diario/2011/11/20/internacional/1321743608 850215.html

Brown, M. R. (2013). Finding Peace by Chile's Troubled Waters: Breaking the Dam of Memories in Ariel Dorfman's Widows. South Central Review, 30(3), 40-60.

Cusato, D. A. (2004). La denuncia de los desaparecidos en Viudas de Ariel Dorfman. En Atti del Convegno di studi su La dittatura di Pinochet e la transizione alla democrazia in Cile: Trastoria e letteratura: Messina, 11-12 novembre 2003 (pp. 57-69). Messina: A. Lippolis.

Dorfman, A. (1996). Viudas. En Teatro 2: Lector, Viudas (pp. 86-191). Buenos Aires: Ediciones de la Flor.

Drake, S. (26 de julio de 1991). Stage Review: Widows an Exercise in Artifice. Los Angeles Times.

Obtenido el 20 de diciembre de 2018 de http://articles.latimes.com/1991-0726/entertainment/ca-45 1 stage-manager

Gomes, L. (2017). Viudas (Ariel Dorfman) e Viúvas (Ói Nóis Aqui Traveiz): entre textos e imagens [Versión electrónica]. Cavalo Louco, 17, 37-45.

Hemispheric Institute Digital Video Library. (2011). Viúvas performance sobre a ausência = Widows: performance about absence. Tribo de Atuadores Ói Nóis Aqui Traveiz collection, Obtenido el 20 de diciembre de 2018 de http://hidvl.nyu.edu/video/hdr7sskd.html 
Hur, S. J. (2013). Evaluación de tres mejores representaciones del año 2012 elegidos por la Asociación Internacional de Críticos Teatrales en Corea. Korean Theatre Journal, 68, 142-144. Isherwood, C. (21 de enero de 2008). The Women Who Protest Deaths of Man After Man. New York Times. Theater. Obtenido el 20 de diciembre de 2018 de https://www.nytimes.com/2008/01/21/theater/reviews/21wido.html

Kim, K. S. (2012). [Teatro (2)] La belleza de recitación del coro y la filosofía de espera: Viudas de Baeksugwangbu. Performances and Reviews, 78, 131-136.

Kim, N. S. (2014). El viento a las espaldas, Viudas. Korean Theatre Journal, 73, 68-72.

Lee, E. K. (2012). Reseña y cuestión: Resistencia para aclarar la verdad de la historia Viudas. Korean Theatre Journal, 66, 46-51.

Mail \& Guardian. (4 de julio de 1997). The Women Who Still Wait. Obtenido el 20 de diciembre de 2018 de https://mg.co.za/article/1997-07-04-the-women-who-still-wait/

McClennen, S. A. (2010). Ariel Dorfman: An Aesthetics of Hope. Durham: Duke University.

Melo, C. (2013). Elegia e alegoria: Caminhos mnemônicos no Teatro do Ói Nóis Aqui Traveiz [Versión electronica]. Cavalo Louco, 13, 20-25.

Milaré, S. (2011). A arte de transformar a realidade em poesia [Versión electrónica]. Cavalo Louco, 10, 49-53.

Propst, A. (18 de enero de 2008). Widows. Theatermania. Obtenido el 20 de diciembre de 2018 de https://www.theatermania.com/new-york-city-theater/reviews/widows 12528.html Sagrado. (2011a). Perfomance sobre a ausência [Entrada en blog]. Obtenido el 20 de febrero de 2019 de https://sagradocacete.wordpress.com/2011/08/11/blog-poaemcena-blogspot-comconfirma-dias-e-horario-perfomance-sobre-a-ausencia/

Sagrado. (2011b). Viúvas - Performance sobre a Ausência no 18ㅇ POA em Cena [Entrada en blog]. Obtenido el 20 de febrero de 2019 de https://sagradocacete.wordpress.com/2011/09/04/\%C2\%A8viuvas-performance-sobre-aausencia\%E2\%80\%9D-no-18\%C2\%BA-poa-em-cena/ 
Shin, S. H. (2018). Widows by Ariel Dorfman. Obtenido el 20 de febrero de 2019 de

\section{http://shshin.creatorlink.net/index/view/18169}

Sommer, E. (13 de enero de 2008). Widows. CurtainUp. Obtenido el 19 de diciembre de 2018 de http://www.curtainup.com/widows.html

Steuernagel, M. (2017). Here We Are Again: Performing the Temporality of the Brazilian Transition. TDR: The Drama Review, 61(4), 9-21.

Sube a escena la obra "Viudas" en el teatro Julia de Burgos de la UPR (9 de noviembre de 2010).

Primera Hora. Obtenido el 16 de marzo de 2019 de

https://www.primerahora.com/entretenimiento/farandula/nota/subeaescenalaobraviudase nelteatrojuliadeburgosdelaupr-442914/

Teatro X la identidad. (2001). Teatro del pueblo. Obtenido el 16 de marzo de 2019 de http://www.teatrodelpueblo.org.ar/obras/ciclo teatro_de la_identidad.htm

Thielman, S. (21 de enero de 2008). Widows. Variety. Obtenido el 20 de diciembre de 2018 de https://variety.com/2008/legit/reviews/widows-2-1200548872/

Teatro Sidarte. (2017). Viudas/EXIT. Obtenido el 20 de diciembre de 2018 de http://www.teatrosidarte.cl/cartelera_sidarte/viudas-exit/. 